\title{
Gene therapy and regenerative tissue engineering in congenital heart disease
}

\author{
Francesco Nappi ${ }^{1}$, Sanjeet Singh Avatar Singh ${ }^{2}$ \\ ${ }^{1}$ Cardiac Surgery, Centre Cardiologique du Nord de Saint-Denis (CCN), Paris, France; ${ }^{2}$ Department of Cardiothoracic Surgery, Golden Jubilee \\ National Hospital, Glasgow, UK \\ Correspondence to: Francesco Nappi, MD. Cardiac Surgery, Centre Cardiologique du Nord de Saint-Denis (CCN), 36 Rue des Moulins Gémeaux, \\ 93200 Saint-Denis, Paris, France. Email: francesconappi2@gmail.com.
}

Submitted Feb 17, 2019. Accepted for publication Apr 16, 2019.

doi: $10.21037 /$ tp. 2019.04 .10

View this article at: http://dx.doi.org/10.21037/tp.2019.04.10

Gene therapy in genetic heart disease is a very attractive topic within the scientific community especially as some congenital heart diseases have been treated in with genome manipulation (1). Two years after its complete affirmation, the precise editing of the genome with CRISPR-Cas9 technology (2) has allowed researchers and clinicians to enter a new era of higher-level genetic engineering and more precise gene therapy; however, the implementation of such concepts remain lagging behind. Furthermore, the availability of centres with advanced technologies in gene therapy and the inherent challenges associated with their practice have limited their widespread use. In addition, the dissemination of scientific information that often precedes solid scientific results does not contribute to clarifying this new therapeutic option for genetic diseases. Recently, the Italian press highlighted the treatment of Hunter syndrome through the manipulation of the human genome, whereas the scientific journals were yet to publish the results. This news was broadcasted immediately after the publication, in August 2017, in Nature (1), on the possibility of using embryos for research and therapy that has rekindled a longstanding debate regarding which precise rules should the research on the human genome be authorized.

The 44-year-old patient with Hunter syndrome was first treated with self-DNA manipulation, known as "Zinc Fingers" at Benioff Children's Hospital of Oakland. Hunter syndrome is a type of mucopolysaccharidosis where a deficiency of iduronate-2-sulphatase (I2S), the enzyme responsible for the catabolism of mucopolysaccharides or glycosaminoglycans (GAG), favors lysosomal accumulation of dermatan sulfate (DS) and heparan sulfate (HS) $(3,4)$. Clinical evidence of Hunter syndrome is damage to organs and tissues including the respiratory tract, heart, brain, liver, spleen, bones and cartilages (5). Heart manifestations of Hunter syndrome include cardiomegaly, a pan-systolic mitral regurgitation (MR) murmur frequently associated with hepatosplenomegaly, mimicking rheumatic disease with multiple heart valve involvement. Progression to heart failure is rapid with most patients already in NYHA Class III needing single or multiple valve replacement(s) (6). Moreover, changes in tissue stroma on the face and neck are also visible with serious psychological implications to the affected person. In patients with Hunter syndrome, enzyme production may be resumed by administering a healthy gene to replace the gene that is responsible for the defective lysosomal enzyme, to the liver cell; a favorable reservoir for the required amount of protein.

The genome manipulation procedure takes utilizes a suitably modified virus, as a vector, to introduce a functioning gene into the liver cell. The right information and specific instructions are aimed at molecules called "Zinc Fingers" that insert the right gene for the production of the enzyme. This is the first time this technique of genome editing has been used in humans, and was previously only reserved for the animal model, thus representing a progressive leap in the field of genetics. The undisputed advantage is that the new healthy gene produces albumin as opposed the faulty one (7), resulting in enzyme production. In the past few years, the use of Crispr-Casg9 has greatly superseded the method of "Zinc Fingers" for genome editing in congenital heart disease allowing considerable success by means of "size and sewing". For example, in August, Nature published a manuscript of Shoukhrat Mitalipov that corrected a pathogenic heterozygous gene mutation 
MYBPC3 related to hypertrophic cardiomyopathy (1) in human embryos with precise CRISPR-Cas9 (2). This study received extensive scientific diffusion compared to the previous one and was discussed and criticized by international experts post-publication. This discussion included the right to claim this possibility, from the opportunity to test data, methodology and queries regarding bioethics.

The enviable effort was produced by a number of suitably coordinated specialists to cure a rare disease, highlighting that scientific processes are applied not only to the most common diseases and to the large part of the population, but also to a select population with rare genetic diseases in small numbers. Scientific progresses such as these are always decisive and well accepted for the welfare of the human population. However, some caution and critical attitudes are expected, because they are not raised from competing geneticists at ground level, and supported by cardiac surgeons interested in the specific cardiac and cardiovascular complications caused by some of these genetic diseases. Therefore, important scientific events must be preceded and accompanied by publications that describe in detail the applied methodology and results to ensure clarity. The concern is linked to the speed by which some scientific innovations are presented to the public, without waiting for the trial period that is indispensable for the certainty of the success of the research. Another non-negligible aspect, concerns the involvement of the individual person who guides the sphere of social behaviour and bioethics. Certainly, the modification of the human genome for therapeutic purposes is a new frontier to be explored, but caution and reasoning are required in the presence of human embryos. Are these methods risk-free? Are the sophisticated techniques presented are reproducible with other heterozygous mutations? and are we sure there are not many other scientific considerations to be done before clinical application is possible?

Another field of scientific interest, an alternative to genetic therapy, is the development of bioabsorbable materials such as those used for the reinforcement of allogeneic tissues. Its potential application in cardiac surgery is in congenital aortic stenosis, in bicuspid aortic valve disease and in the pathologies of the left ventricular outflow tract. These cardiac diseases can be treated with the Ross operation. Newborns and children are favourable candidates to receive pulmonary autograft root insertion to replace aortic valve diseased and/or LVTO although the results are less favourable especially when compared to the adult population, as pulmonary autograft (PA) root (PAR) dilatation plays a major role in long-term outcomes. Accumulating evidence suggest that patients with bicuspid aortic valve and aortic regurgitation have a higher risk of increased pulmonary autograft root diameter thus, a higher risk of failure with shortened durability. Mechanical phenomena related to the dilatation of pulmonary autograft under systemic pressure have recently been studied highlighting the biomechanics of PA (8-20). Mookhoek et al. (8) evidenced that the failed PA had a nonlinear response to mechanical loading, typical of healthy human arterial tissue, as nonlinear stress-strain response was present in both failed PA and normal PAR. Evidence of a remodelling process was shown in failed explanted conduits with increased wall thickness and decreased stiffness. The authors concluded that the increased compliance may explain progressive autograft root dilatation in autograft failures. An external barrier may prevent late dilatation and failure of pulmonary autograft root. Primary experience with an inclusion cylinder technique with the native aorta and a synthetic external support, such as Dacron was performed to stabilize the autograft root and improve longterm outcomes (9,10,21-23). Concerns regarding external reinforcement of a Dacron prosthetic graft is related to the PA which results in a straight material that would encase and dramatically impaired the PA pulsatility and compliance. We previously showed the negative effect of Dacron grafts and other synthetic polyesters that severely impair aortic compliance. Their use as vascular replacement for reinforcement of PA may be determined by a strong inflammatory reaction with significant damage to vessel walls (18-20).

Two factors merit further discussion. First, the aortic root anatomy presents an increased degree of complexity and cannot be approximated to by cylindrical geometry. Second, material deformation occurs not only in axial and lateral fashions, but also via shear stress should also be applied to determine the sliding of the conduit components.

To solve these issues, we have selected a material suitable to comply with both shear stress requirements and differential dilation tendency of the root. We have chosen ePTFE that is currently used in surgery and known, from the elastomechanical standpoint, to have auxetic behaviour $(9,10,16)$. The component of ePTFE fibers when subjected to a tensile stress "open up" structurally and expand in the direction transverse to the stress; conversely, if these materials are subjected to compression, they structurally "close" $(16,17)$. Our results favoured the development of 
a semi-resorbable composite scaffold aimed at reinforcing the pulmonary autograft during the Ross procedure $(9,10,16,17)$. This cross-linked bioresorbable prosthesis provided increased stability and solidity to the neo-aortic root, preventing the dilation of PAR due to systemic pressure. The composite prosthesis made with ePTFE and polydioxanone (PDS) prevented pulmonary autograft dilation and promoted connective remodelling of the pulmonary autograft wall resulting in a neo-vessel formation $(9,10,12,19)$. The final result was an increased elastin content of PA with potentially improved biomechanical properties $(16,19,24)$.

In conclusion the future of treatment of many congenital heart diseases is with improvements of genetic practices for clinical application and tissue engineering (25). This basic path must be united by solid scientific research.

\section{Acknowledgments}

None.

\section{Footnote}

Conflicts of Interest: The authors have no conflicts of interest to declare.

\section{References}

1. Ma H, Marti-Gutierrez N, Park SW, et al. Correction of a pathogenic gene mutation in human embryos. Nature 2017;548:413-9.

2. Salsman J, Dellaire G. Precision genome editing in the CRISPR era. Biochem Cell Biol 2017;95:187-201.

3. Whiteman DA, Kimura A. Development of idursulfase therapy for mucopolysaccharidosis type II (Hunter syndrome): the past, the present and the future. Drug Des Devel Ther 2017;11:2467-80.

4. Demydchuk M, Hill CH, Zhou A, et al. Insights into Hunter syndrome from the structure of iduronate-2sulfatase. Nat Commun 2017;8:15786.

5. Bradley LA, Haddow HRM, Palomaki GE. Treatment of mucopolysaccharidosis type II (Hunter syndrome): results from a systematic evidence review. Genet Med 2017;19:1187-201.

6. Madireddi J, Sarada P, Shetty RK, et al. Hunter syndrome with its typical heart: a close mimic to rheumatic heart. BMJ Case Rep 2015. doi: 10.1136/bcr-2015-209359.

7. Sharma R, Anguela XM, Doyon Y, et al. In vivo genome editing of the albumin locus as a platform for protein replacement therapy. Blood 2015;126:1777-84.

8. Mookhoek A, Krishnan K, Chitsaz S, et al. Biomechanics of Failed Pulmonary Autografts Compared With Normal Pulmonary Roots. Ann Thorac Surg 2016;102:1996-2002.

9. Nappi F, Spadaccio C, Castaldo C, et al. Reinforcement of the pulmonary artery autograft with a polyglactin and polydioxanone mesh in the Ross operation: experimental study in growing lamb. J Heart Valve Dis 2014;23:145-8.

10. Nappi F, Spadaccio C, Fouret P, et al. An experimental model of the Ross operation: Development of resorbable reinforcements for pulmonary autografts. J Thorac Cardiovasc Surg 2015;149:1134-42.

11. Nappi F, Spadaccio C, Al-Attar N, et al. The Ross procedure at the crossroads: lessons from biology: is $\mathrm{Dr}$ Ross's dream concluded? Int J Cardiol 2015;178:37-9.

12. Spadaccio C, Montagnani S, Acar C, et al. Introducing bioresorbable scaffolds into the show. A potential adjunct to resuscitate Ross procedure. Int J Cardiol 2015;190:50-2.

13. Nappi F, Spadaccio C, Chello M, et al. The Ross procedure: Underuse or under-comprehension? J Thorac Cardiovasc Surg 2015;149:1463-4.

14. Nappi F, Spadaccio C, Acar C, et al. The future of Ross procedure. Ann Pediatr Cardiol 2015;8:256-7.

15. Nappi F, Spadaccio C, Fraldi M, et al. Use of bioresorbable scaffold for neopulmonary artery in simple transposition of great arteries: Tissue engineering moves steps in pediatric cardiac surgery. Int J Cardiol 2015;201:639-43.

16. Nappi F, Spadaccio C, Fraldi M, et al. A composite semiresorbable armoured scaffold stabilizes pulmonary autograft after the Ross operation: Mr Ross's dream fulfilled. J Thorac Cardiovasc Surg 2016;151:155-64.e1.

17. Nappi F, Carotenuto AR, Di Vito D, et al. Stressshielding, growth and remodeling of pulmonary artery reinforced with copolymer scaffold and transposed into aortic position. Biomech Model Mechanobiol 2016;15:1141-57.

18. Nappi F, Carotenuto AR, Cutolo A, et al. Compliance mismatch and compressive wall stresses drive anomalous remodelling of pulmonary trunks reinforced with Dacron grafts. J Mech Behav Biomed Mater 2016;63:287-302.

19. Nappi F, Fraldi M, Spadaccio C, et al. Biomechanics drive histological wall remodeling of neoaortic root: A mathematical model to study the expression levels of ki 67 , metalloprotease, and apoptosis transition. J Biomed Mater Res A 2016;104:2785-93.

20. Spadaccio C, Nappi F, Al-Attar N, et al. Old Myths, New Concerns: the Long-Term Effects of Ascending Aorta 
Replacement with Dacron Grafts. Not All That Glitters Is Gold. J Cardiovasc Transl Res 2016;9:334-42.

21. Carrel T, Schwerzmann M, Eckstein F, et al. Preliminary results following reinforcement of the pulmonary autograft to prevent dilatation after the Ross procedure. J Thorac Cardiovasc Surg 2008;136:472-5.

22. Skillington PD, Mokhles MM, Takkenberg JJ, et al. The Ross procedure using autologous support of the pulmonary autograft: techniques and late results. J Thorac Cardiovasc Surg 2015;149: S46-52.

23. Carrel T. The autograft inclusion: an obligatory step to

Cite this article as: Nappi F, Singh SS. Gene therapy and regenerative tissue engineering in congenital heart disease. Transl Pediatr 2019;8(5):356-359. doi: 10.21037/tp.2019.04.10 avoid late failure following the Ross procedure? J Thorac Cardiovasc Surg 2015;149:S53-4.

24. Nappi F, Nenna A, Larobina D, et al. Simulating the ideal geometrical and biomechanical parameters of the pulmonary autograft to prevent failure in the Ross operation. Interact Cardiovasc Thorac Surg 2018;27:269-76.

25. Spadaccio C, Nappi F, De Marco F, et al. Preliminary In Vivo Evaluation of a Hybrid Armored Vascular Graft Combining Electrospinning and Additive Manufacturing Techniques. Drug Target Insights 2016;10:1-7. 